\title{
Cataract-hypertrichosis-intellectual disability syndrome
}

INSERM

\section{Source}

INSERM. (1999). Orphanet: an online rare disease and orphan drug data base. Cataracthypertrichosis-intellectual disability syndrome. ORPHA:1375

Cataract-hypertrichosis-intellectual disability syndrome is characterized by congenital cataract, generalized hypertrichosis and intellectual deficit. It has been described in two Egyptian sibs born to consanguineous parents. It is transmitted as an autosomal recessive trait. 